\title{
Elaboration and Characterization of a Composite Material Based on Canarium schweinfurthii Engl Cores with a Polyester Matrix
}

\author{
Dieunedort Ndapeu, ${ }^{1,2}$, Francis Tamwo ${ }^{1,2}$, Morino Bernard Nganou Koungang3, \\ Ghislain Tchuen ${ }^{1,2}$, Nicodème R. Sikame Tagne ${ }^{1,2}$, Sophie Bistac ${ }^{4}$, Ebénezer Njeugna ${ }^{3}$
}

\author{
${ }^{1}$ Research Unit of Industrial Systems and Environmental Engineering (URISIE), UIT-FV Bandjoun, University of Dschang, \\ Bandjoun, Cameroon \\ ${ }^{2}$ Research Unit of Mechanics and Physical Systems Modelling (UR2MSP), Department of Physics, University of Dschang, \\ Dschang, Cameroon \\ ${ }^{3}$ Mechanics and Adapted Materials Laboratory (LAMMA), ENSET, Douala, Cameroon \\ ${ }^{4}$ Physics and Macromolecular Engineering Laboratory (LPIM), UHA, Mulhouse, France \\ Email:ndapeu@yahoo.fr
}

How to cite this paper: Ndapeu, D., Tamwo, F., Nganou Koungang, M.B., Tchuen, G., Sikame Tagne, N.R., Bistac, S. and Njeugna, E. (2020) Elaboration and Characterization of a Composite Material Based on Canarium schweinfurthii Engl Cores with a Polyester Matrix. Materials Sciences and Applications, 11, 204-215. https://doi.org/10.4236/msa.2020.113014

Received: January 28, 2020

Accepted: March 16, 2020

Published: March 19, 2020

Copyright $\odot 2020$ by author(s) and Scientific Research Publishing Inc. This work is licensed under the Creative Commons Attribution International License (CC BY 4.0).

http://creativecommons.org/licenses/by/4.0/

\begin{abstract}
The aim of this work was to develop and characterize a polyester matrix composite material based on Canarium schweinfurthii Engl core granule. The particle size and the mass fractions of these cores used as fillers in this composite were the two optimization parameters. The experimentation of the twelve sample areas was based on the following optimization parameters: Three particles sizes of $80<\mathrm{T}_{1}<160 \mu \mathrm{m}, 160<\mathrm{T}_{2}<315 \mu \mathrm{m}$ and $315<\mathrm{T}_{3}<$ $630 \mu \mathrm{m}$ and four mass fractions of $0 \%, 40 \%, 45 \%$ and $50 \%$. The composites were produced by hand lay-up method. The physical and mechanical parameters concerned by this study are: absolute density, compressive stress at break, Young's modulus in bending and coefficient of static friction with wood. Each of these parameters was determined by testing ten specimens per sampling area. It was found that the absolute density varies very little as a function of particle size and mass fraction. This absolute density is between 1200 and $1232 \mathrm{~kg} \cdot \mathrm{m}^{-3}$, which allows us to admit that this composite belongs to the family of light materials. The maximum compressive stress at break was obtained for the formulation $40 \%$ filler of size $\mathrm{T}_{3}$. This compressive stress at maximum rupture is in the range of $199.14 \mathrm{MPa}$. From $0 \%$ to $45 \%$ of filler, the flexural Young's modulus of the composite increases whatever the particle size. The highest value is obtained for $\mathrm{T}_{2}$ particle size, i.e. $13.11 \mathrm{GPa}$. The static friction coefficient of the composite on wood increases as the filler con-
\end{abstract}


tent varies from 0.30 to 0.42 . Thus, in view of the properties obtained, this composite can be used as alternative solutions in industrial applications, for the manufacturing of shoe heel, house ceiling, floors for housing and table support.

\section{Keywords}

Canarium schweinfurthii Engl, Characterization, Composite, Polyester, Filler

\section{Introduction}

Developing countries derive most of their income from agriculture. From this agriculture generally come plant by-products, among which plant hard shells and cores figure prominently. These hard cores include those of the Canarium schweinfurthii Engl, which is an oilseed of the Burseraceae family, with an ellipsoidal drupe that turns green when it grows and turns purplish at maturity [1] This oilseed has a pulp and a hard core with an almond inside. This pulp is edible and is part of the food habits of the populations of the dense equatorial forests [2]. Generally after consumption of the pulp, the kernels are dumped into nature causing a pollution problem by their massive presence accompanied by their slow degradation. It should be noted that about $68 \%$ of these cores are dumped in the wild after a harvest season, due to the lack of reliable storage facilities that can ensure their availability over the years [3]. Fruit production generally experiences two flowering periods during the year, between September and March. As the production season passes, with the massive presence of these pits in the environment, it can be seen that they pose many problems to the population. In addition to the pollution problems posed by these pits, they cause bodily harm when they are inadvertently trampled on and crack the windshields of cars when they are thrown.

In the literature, many works have been done on the Canarium schweinfurthii Engl cores. Yilleng et al. (2013) studied the use of these cores as activated carbon [4]. Ehiem et al. (2015) determined the coefficient of friction of these cores with wood, formica and their interaction with moisture content. The results obtained showed that the coefficient and angle of static friction of Canarium schweifurthii small and long varieties increased linearly with decrease in moisture content and shape [5]. Obi et al. (2018) determined the physical and aerodynamic characteristics of the Canarium schweinfurthii Engl cores [6]. The water absorption characteristics of these cores have been studied and the moisture bearing capacity, textural, and nutritive qualities of the reconstituted products showed no significant difference among varieties at different temperatures used [7]. Ehiem et al. (2019) studied the moisture flux of these cores and results obtained showed that all the flow properties increased with an increase in the moisture content except for the coefficient of mobility [3]. The physical parameters of Canarium schweinfurthii Engl fruit decreased linearly with a decrease in moisture content [8]. 
The development in science and technology required a variety of polymer with good properties and low cost. Therefore, polymer composites were considered to be among the more promising approaches to yield new materials and have been investigated extensively. In recent years, many studies have been dedicated to utilizing lignocellulosic fillers such as coconut shell, wood, pineapple leaf, palm kernel shell, etc. as fillers in order to replace synthetic fillers through utilization of natural fillers or reinforcement in thermoplastic and thermoset polymer composites in an attempt to minimize the cost, increase productivity and enhance mechanical properties of product [9].

Extensive studies on the preparation and properties of thermosetting and thermoplastic composites filled with jute, sisal, coconut shell, coir, bagasse, Rice-husk etc. have been investigated. The use of biomaterials in general and agro-waste in particular is a subject of great interest nowadays not only from the technological and scientific points of view but also socially and economically in terms of employment, cost and environmental issues [10].

So far no work has been done on the development of a composite based on these particulates. Unsaturated Polyester and urea formaldehyde resins are the two most available matrices in Cameroon, among which unsaturated polyester resins are used extensively in the composites industry because of their good mechanical properties, low cost and ease of use [11] and [12].

In the light of the above, the present study is channeled towards producing a composite material using a thermoset polymer (Unsaturated polyester) as the matrix and a lignocellulosic material (Canarium Schweinfurthii Engl cores (NCS) particulates) as the reinforcing filler so as to further establish the use of agricultural wastes as reinforcements in polymer matrices. Also the study tends to use mechanical and physical properties as criteria in establishing the possibility of using lignocellulosic materials as reinforcing fillers in thermoset polymers.

\section{Materials and Methods}

\subsection{Materials}

The fruits of Canarium Schweinfurthii Engl whose cores are exploited in this study come from the same tree in the Bayangam subdivision from West Cameroon Region; Figure 1 below illustrates the anatomy of the fruit in question. Unsaturated polyester resin containing styrene and its hardener or catalyst (methyl ethyketone peroxide) have been brought in the local market.

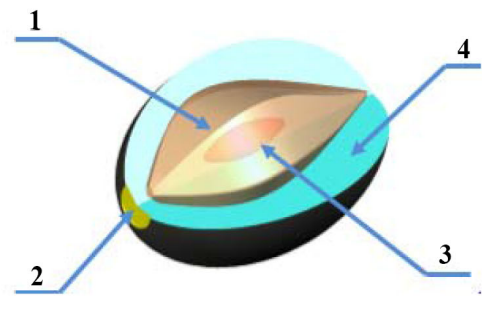

Legend:

1-Core

2-Stalk spot

3-Grain or almond 4-Pulp

Figure 1. Anatomy of the Canarium schweinfurtii Engl fruit. 


\subsection{Processing}

After harvesting, separation of the core from the pulp was achieved by softening the pulp in hot water. The optimal couple: heating water temperature/holding time at this temperature, leading to softening of the fruit, is between $50^{\circ} \mathrm{C} / 10 \mathrm{~min}$ and $55^{\circ} \mathrm{C} / 20 \mathrm{~min}$ [2]. After the separation of the pulp from the cores, the cores were cleaned in an aqueous solution to remove traces of oil. Afterwards, the water contained in the cores was dried by placing them in an oven set at $105^{\circ} \mathrm{C}$ for 2 hours to release the inner layer (almond) of the core. This phase is followed by the crushing of the cores and then winnowing to separate the almond from the shells. After obtaining the shells, we had them crushed, using a hammer mill; in order to obtain the powdered particles of Canarium schweinfurthii Engl (CS) cores as shown in Figure 2.

\subsection{Particle Size Analysis}

After obtaining the powdered particles, the sieve sizes 80, 160, 315 and $630 \mu \mathrm{m}$ were used to determine the various usable grain sizes by sieve analysis method. About $5285.8 \mathrm{~g}$ of CS powder was put over the sieve shaker and shaken it for 20 min, after this operation, we have obtained a distribution of granule sizes according to the masses of granules, as presented in Table 1.

\subsection{Sample Preparation and Moulding}

In order to reduce the environmental pollution caused by these cores, we decided to use higher volume fractions of filler. The basic formulation result shown that, there was no good cohesion between the filler and the resin above $50 \%$ filler. So for the rest of our work, we decided to use the fractions $40 \%, 45 \%$ and $50 \%$ filler for the preparation of sample in comparison of a sample made up without incorporated filler (0\%). Then for the formulation of the composite, 4 discontinuous ranges of filler content and 3 grain sizes were used according to Table 2.

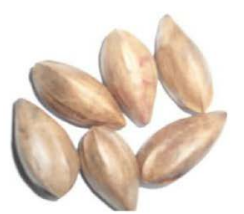

(a)

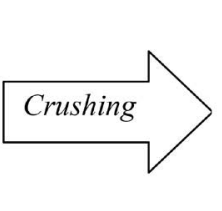

(b)

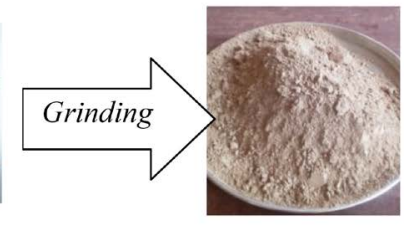

(c)

Figure 2. Production cycle of CS aggregates. (a) CS cores; (b) CS shell; (c) CS shell powder.

Table 1. Filler size distribution versus filler mass.

\begin{tabular}{cccccc}
\hline Size $(\mu \mathrm{m})$ & $80<\mathrm{T}_{1}<160$ & $160<\mathrm{T}_{2}<315$ & $315<\mathrm{T}_{3}<630$ & $\mathrm{~T}_{4}>630$ & Total \\
\hline Mass $(\mathrm{g})$ & 656.4 & 1602.2 & 1887.6 & 1139.6 & 5285.8 \\
Mass $(\%)$ & 12.42 & 30.31 & 35.71 & 21.56 & 100 \\
\hline
\end{tabular}

Sizes $\mathrm{T}_{1}, \mathrm{~T}_{2}$ and $\mathrm{T}_{3}$ have been used in this work. 
Table 2. Composite formulation matrix.

\begin{tabular}{ccccc}
\hline & \multicolumn{4}{c}{ \%filler content } \\
\cline { 2 - 5 } Aggregate size & 0 & 40 & 45 & 50 \\
\hline $\mathrm{T}_{1}$ & $0 \mathrm{~T}_{1}$ & $40 \mathrm{~T}_{1}$ & $45 \mathrm{~T}_{1}$ & $50 \mathrm{~T}_{1}$ \\
$\mathrm{~T}_{2}$ & $0 \mathrm{~T}_{2}$ & $40 \mathrm{~T}_{2}$ & $45 \mathrm{~T}_{2}$ & $50 \mathrm{~T}_{2}$ \\
$\mathrm{~T}_{3}$ & $0 \mathrm{~T}_{3}$ & $40 \mathrm{~T}_{3}$ & $45 \mathrm{~T}_{3}$ & $50 \mathrm{~T}_{3}$ \\
\hline
\end{tabular}

The samples have been codified as shown in Table 3 .

The volume fractions of the components were determined using the masses of each component through the principle of mixture law. Polyester and hardener were mixed in a container and stirred well for $1-2$ minutes. Before the mixture was placed inside the mould, the mould has initially been polished with a release agent to prevent the composites from sticking onto the mould upon removal. Finally, the mixture was poured into the mould with four compartments of identical dimensions $150 \mathrm{~mm} \times 75 \mathrm{~mm} \times 12 \mathrm{~mm}$, and left at room temperature for 3 hours until the mixture was hardened by hand lay-up method. When the composite was hardened, it was removed from the mould and placed inside an oven for 3 hours at $105^{\circ} \mathrm{C}$ for curing. Figure 3 shows the procedure for processing our samples.

\subsection{Determination of the Density}

The density was determined using pycnometers by the method of successive weighing according to standard NF P 94-054 [13]. After drying at $105^{\circ} \mathrm{C}$ for 4 hours, ten specimens of dimension $35 \mathrm{~mm} \times 35 \mathrm{~mm} \times 10 \mathrm{~mm}$ for sample were used.

\subsection{Compression Testing}

The compression test was conducted using the universal compression testing machine. We used ten specimens of dimensions $15 \mathrm{~mm} \times 15 \mathrm{~mm} \times 15 \mathrm{~mm}$, in each category.

The specimen was placed between two plates. The test consists of compressing this specimen until breakage.

By increasing the compressive force to be applied to the specimen until breakage in order to obtain the maximal compressive stress at breakage.

\subsection{Flexural Testing}

Flexural test was performed using three point bending method according to ASTM D790-03 procedure shown in Figure 4. This test consists of subjecting a specimen resting on two simple supports to a concentrated effort in its middle as shown in Figure 4.

Ten specimens of each sample of section $b \times e=15 \times 1.2 \mathrm{~mm}^{2}$ and length $L=$ $150 \mathrm{~mm}$ of our composite were subjected to 3 -point bending. For this purpose, 
Table 3. Sample codification.

\begin{tabular}{cc}
\hline Sample code & \multicolumn{1}{c}{ Designation } \\
\hline $0 \mathrm{CT}$ & Composite realized with $0 \%$ of filler content \\
$40 \mathrm{CT}_{1}$ & composite with $40 \%$ of filler content of particle sizes between 80 and $160 \mu \mathrm{m}$. \\
$45 \mathrm{CT}_{1}$ & composite with $45 \%$ of filler content of particle sizes between 80 and $160 \mu \mathrm{m}$. \\
$50 \mathrm{CT}_{1}$ & composite with $50 \%$ of filler content of particle sizes between 80 and $160 \mu \mathrm{m}$. \\
$40 \mathrm{CT}_{2}$ & composite with $40 \%$ of filler content of particle sizes between 160 and $315 \mu \mathrm{m}$. \\
$45 \mathrm{CT}_{2}$ & composite with $45 \%$ of filler content of particle sizes between 160 and $315 \mu \mathrm{m}$. \\
$50 \mathrm{CT}_{2}$ & composite with $50 \%$ of filler content of particle sizes between 160 and $315 \mu \mathrm{m}$. \\
$40 \mathrm{CT}_{3}$ & composite with $40 \%$ of filler content of particle sizes between 315 and $630 \mu \mathrm{m}$. \\
$45 \mathrm{CT}_{3}$ & composite with $45 \%$ of filler content of particle sizes between 315 and $630 \mu \mathrm{m}$. \\
$50 \mathrm{CT}_{3}$ & composite with $50 \%$ of filler content of particle sizes between 315 and $630 \mu \mathrm{m}$. \\
\hline
\end{tabular}

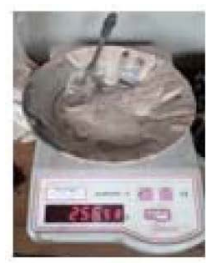

(a)

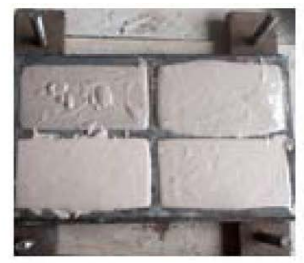

(b)

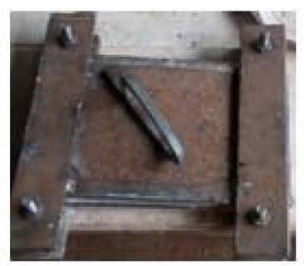

(c)

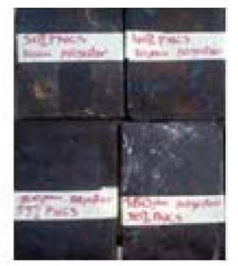

(d)

Figure 3. Process for obtaining our composites: (a) measuring and homogeneous mixing of the components, (b) moulding of the mixture, (c) hand lay-up method, (d) composites obtained after curing.
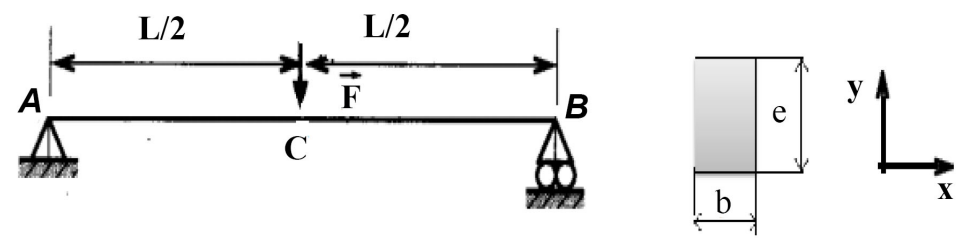

Figure 4. Schematic diagram of the 3-point bending test.

the universal bending-compression testing machine of CONTROLS brand was used. The tests carried out at room temperature consisted in imposing the load $F$ in increments. For each value of $F$, the deflection $y_{c}$ from point $\mathrm{C}$ was taken with the help of a digital comparator with a precision of 0.001 . The slope $a$ of the linear part of the curve of $F$ as a function of $y_{c}$ makes it possible to deduce the bending Young's modulus $E$ from Equation (1) below.

$$
E=\frac{\alpha L^{3}}{48 I}
$$

where $I$ is the quadratic moment of the cross-section of the sample.

\subsection{Static Friction Coefficient on Wood}

The static coefficient of friction was determined experimentally according to 
Coulomb's law. For each test, a sample of mass $\mathrm{m}$ is placed on the AC side of Figure 5, made with wood sanded with class 80 sandpaper, in a pivotal connection with the $\mathrm{AB}$ side which is fixed. The angle $\theta$ is varied slowly and progressively from $0^{\circ}$ to the value $\theta_{\max }$ at which the sample starts to move. The static friction coefficient $\mu_{s}$ is calculated by Equation (2).

$$
\mu_{s}=\frac{F_{t}}{F_{N}}=\frac{m g \sin \theta_{\text {max }}}{m g \cos \theta_{\text {max }}}=\tan \theta_{\text {max }}
$$

\section{Results and Discussion}

\subsection{Density}

The mean value and standard deviation of the density for each sample used are presented in Table 4.

Figure 6 illustrates the variation of the density with filler content.

It can be seen that there is a slight variation of the density in the sample field and it lies between 1200 and $1232.10 \mathrm{~kg} \cdot \mathrm{m}^{-3}$.

\subsection{Compression Testing}

After compression testing, the mean value and standard deviation of the maximal compressive stress for each sample used are presented in Table 5.

Figure 7 shows the change in compressive stress at break versus filler content.

It can be seen from Figure 7 that the compressive stress at break has the same rate for all three sizes and reaches its maximum value at $40 \%$ filler content. The gap between $0 \%$ and $40 \%$ filler content is due to the fact that it is only after $40 \%$ filler content that the composite is consistent.

\subsection{Flexural Testing}

After this testing procedure, the mean value and standard deviation of the flexural Young modulus for different sample used are presented in Table 6.

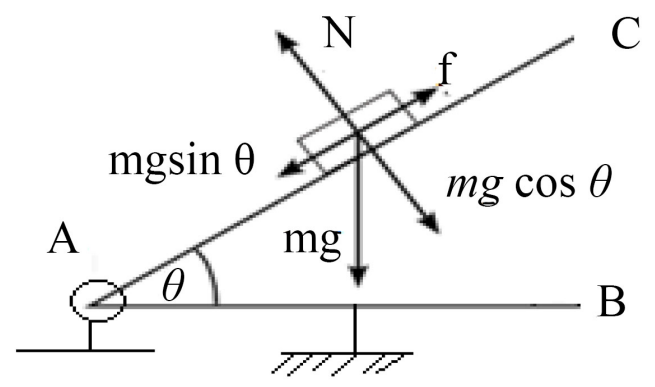

Figure 5. Illustration of the determination of the coefficient of static friction.

Table 4. Mean value and standard deviation of the density versus \% filler content.

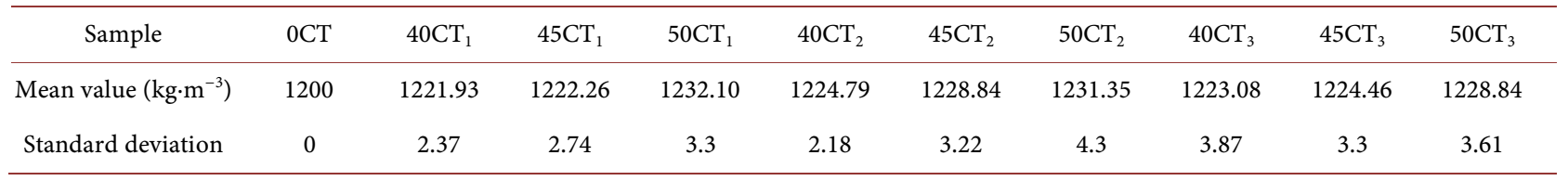


Table 5. Mean value and standard deviation of the maximal compressive stress versus \% filler content.

\begin{tabular}{ccccccccccc}
\hline Sample & $0 \mathrm{CT}$ & $40 \mathrm{CT}_{1}$ & $45 \mathrm{CT}_{1}$ & $50 \mathrm{CT}_{1}$ & $40 \mathrm{CT}_{2}$ & $45 \mathrm{CT}_{2}$ & $50 \mathrm{CT}_{2}$ & $40 \mathrm{CT}_{3}$ & $45 \mathrm{CT}_{3}$ & $50 \mathrm{CT}_{3}$ \\
\hline $\begin{array}{c}\text { Mean value } \\
(\mathrm{MPa})\end{array}$ & 55 & 105.58 & 95.91 & 70.71 & 150.5 & 146.13 & 134.36 & 199.14 & 193.91 & 164.51 \\
$\begin{array}{c}\text { Standard } \\
\text { deviation }\end{array}$ & 0 & 1.77 & 3.43 & 5.08 & 2.87 & 1.36 & 2.44 & 1.38 & 3.62 & 3.12 \\
\hline
\end{tabular}

Table 6. Mean value and standard deviation of the flexural Young modulus versus \% filler content.

\begin{tabular}{ccccccccccc}
\hline Sample & $0 \mathrm{CT}$ & $40 \mathrm{CT}_{1}$ & $45 \mathrm{CT}_{1}$ & $50 \mathrm{CT}_{1}$ & $40 \mathrm{CT}_{2}$ & $45 \mathrm{CT}_{2}$ & $50 \mathrm{CT}_{2}$ & $40 \mathrm{CT}_{3}$ & $45 \mathrm{CT}_{3}$ & $50 \mathrm{CT}_{3}$ \\
\hline $\begin{array}{c}\text { Mean value } \\
(\mathrm{GPa})\end{array}$ & 3.56 & 12.54 & 9.12 & 6.39 & 10.93 & 13.11 & 8.99 & 7.35 & 9.31 & 5.78 \\
$\begin{array}{c}\text { Standard } \\
\text { deviation }\end{array}$ & 0 & 2.47 & 1.6 & 1.31 & 2.28 & 1.98 & 2.06 & 2.45 & 1.08 & 3.21 \\
\hline
\end{tabular}

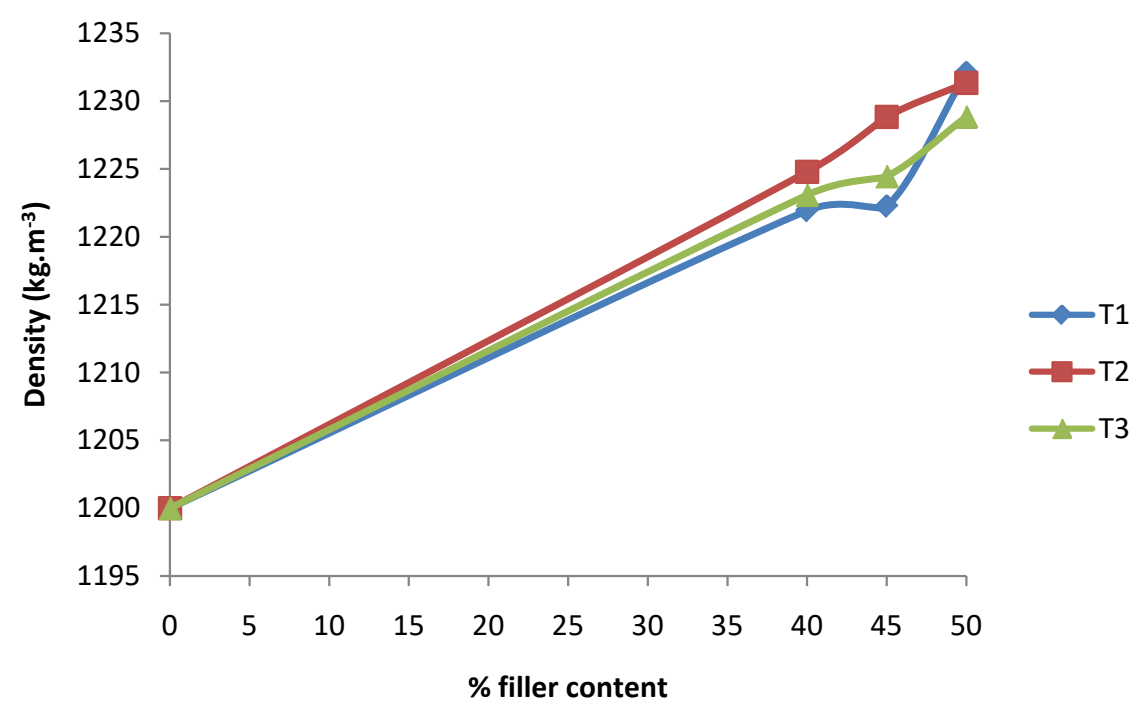

Figure 6. Density versus \% fillers.

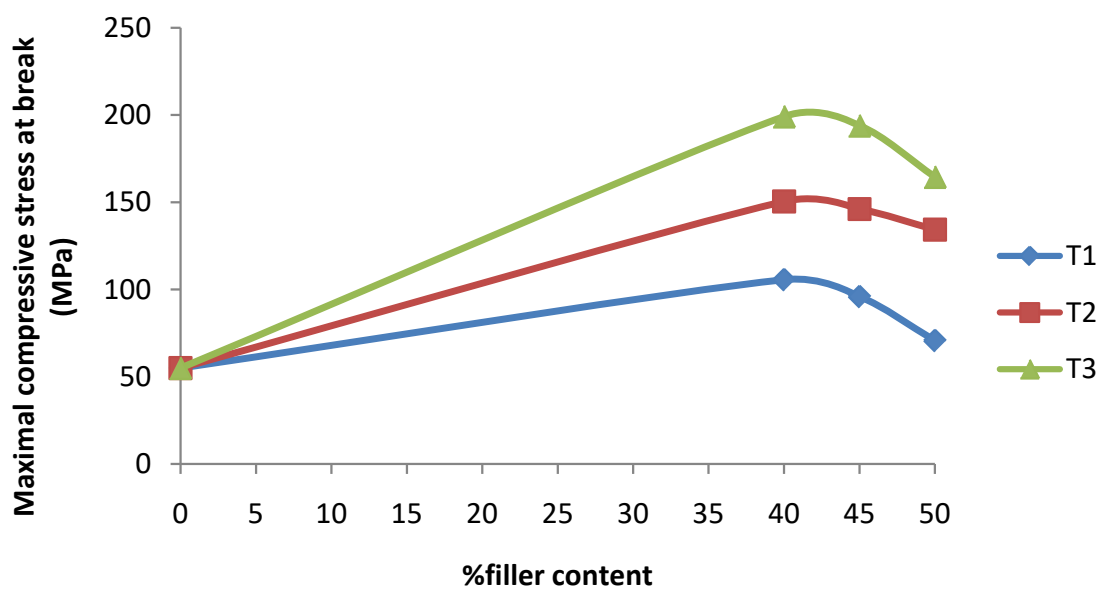

Figure 7. Compressive stress at break versus $\%$ filler content. 
Figure 8 shows the variation of flexural Young modulus with filler content.

It is observed that at $40 \%$ of filler content, formulation $\mathrm{T}_{1}$ is the stiffest, while at $45 \%$ of filler content, formulation $\mathrm{T}_{2}$ is the most rigid.

Up to $45 \%$ filler content, the Young's modulus increases and reaches its maximum of $13.11 \mathrm{GPa}$ at $45 \%$ filler content for a size of $\mathrm{T}_{2}$.

\subsection{Static Coefficient of Friction of Wood/Composite}

The mean value and standard deviation of the friction coefficient for different sample on wood are presented in Table 7.

Figure 9 illustrates the variation in the static friction coefficient of the composite on wood versus filler content.

The static friction coefficient of the composite on wood increases with the filler content and ranged from 0.30 to 0.42 .

Table 8 summarises the properties obtained in comparison with those in the

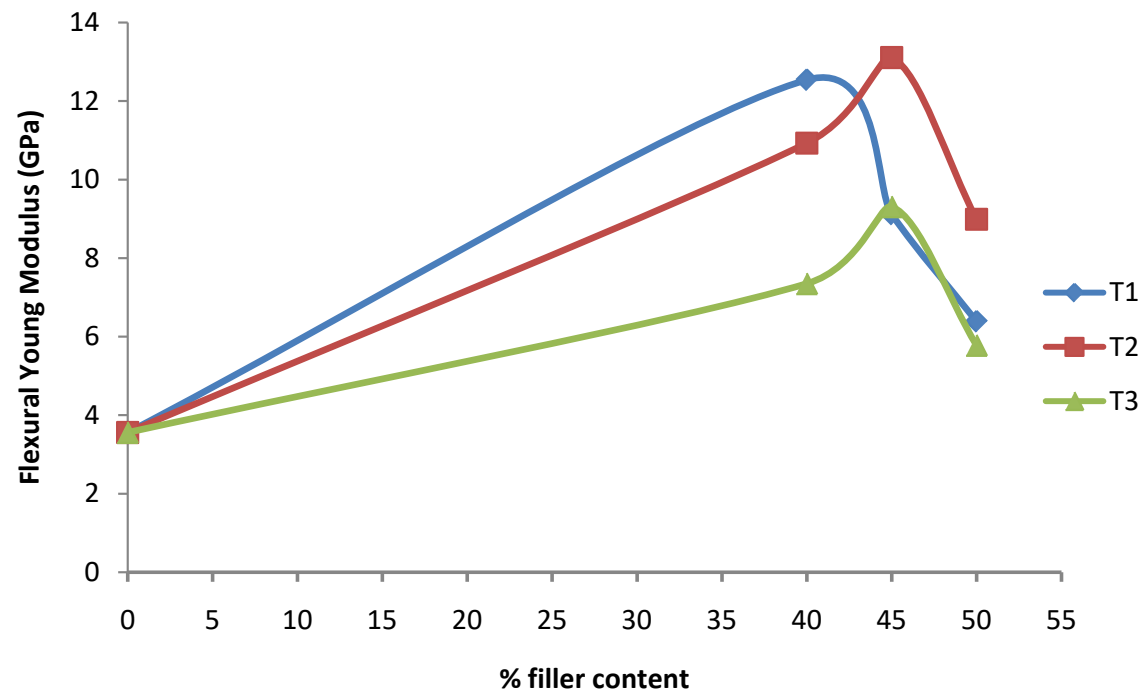

Figure 8. Flexural Young modulus versus \% filler content.

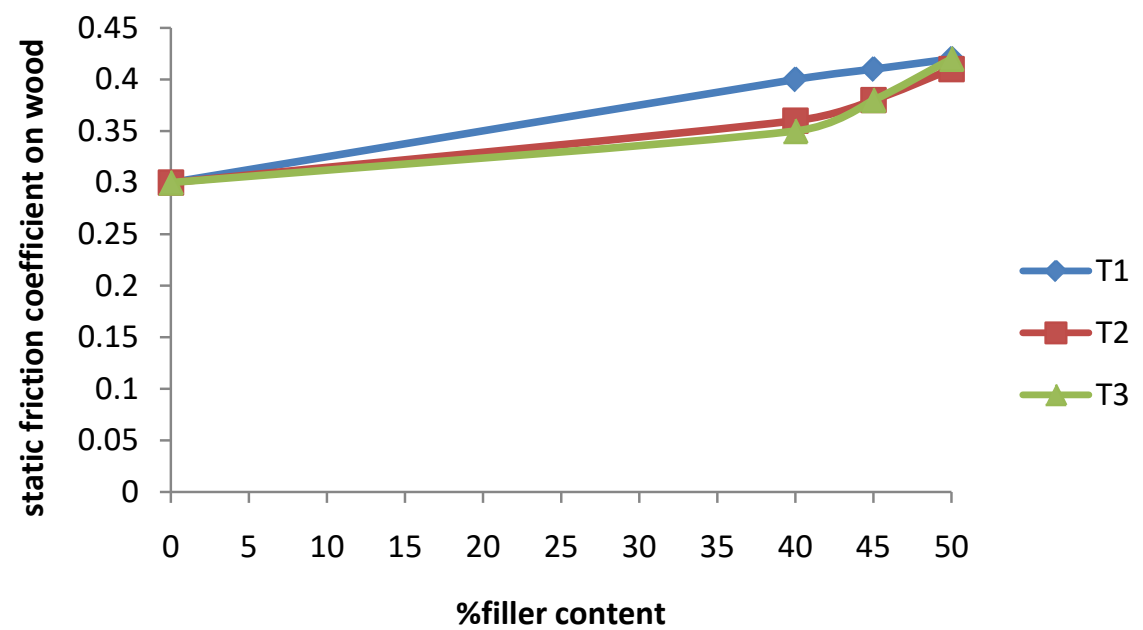

Figure 9. Static friction coefficient on wood versus filler content. 
Table 7. Mean value and standard deviation of the friction coefficient on wood $\%$ filler content.

\begin{tabular}{ccccccccccc}
\hline Sample & $0 \mathrm{CT}$ & $40 \mathrm{CT}_{1}$ & $45 \mathrm{CT}_{1}$ & $50 \mathrm{CT}_{1}$ & $40 \mathrm{CT}_{2}$ & $45 \mathrm{CT}_{2}$ & $50 \mathrm{CT}_{2}$ & $40 \mathrm{CT}_{3}$ & $45 \mathrm{CT}_{3}$ & $50 \mathrm{CT}_{3}$ \\
\hline Mean value & 0.30 & 0.4 & 0.41 & 0.42 & 0.36 & 0.38 & 0.41 & 0.35 & 0.38 & 0.42 \\
$\begin{array}{c}\text { Standard } \\
\text { deviation }\end{array}$ & 0 & 0.018 & 0.019 & 0.013 & 0.02 & 0.017 & 0.011 & 0.016 & 0.021 & 0.028 \\
\hline
\end{tabular}

Table 8. Summary and comparison of results obtained.

\begin{tabular}{|c|c|c|c|c|c|c|c|c|}
\hline \multirow{3}{*}{ Properties } & \multicolumn{5}{|c|}{ CS/polyester composite } & \multirow{3}{*}{$\begin{array}{l}\text { Midrib Coconut Palm } \\
\text { Leaf Reinforced } \\
\text { Polyester Composite }\end{array}$} & \multirow{3}{*}{$\begin{array}{l}\text { Sisall polyester } \\
\text { composite }\end{array}$} & \multirow{3}{*}{$\begin{array}{c}\text { Bambool polyester } \\
\text { composite }\end{array}$} \\
\hline & \multicolumn{4}{|c|}{$\%$ filler content } & \multirow{2}{*}{-Grain size } & & & \\
\hline & 0 & 40 & 45 & 50 & & & & \\
\hline \multirow{3}{*}{$\begin{array}{l}\text { Compressive } \\
\text { stress at break } \\
(\mathrm{MPa})\end{array}$} & 55 & 105.58 & 95.91 & 70.71 & $\mathrm{~T}_{1}$ & \multirow{3}{*}{$\begin{array}{c}77.65 \\
{[14]}\end{array}$} & & \\
\hline & 55 & 150.50 & 146.13 & 134.36 & $\mathrm{~T}_{2}$ & & & \\
\hline & 55 & 199.14 & 193.91 & 164.51 & $\mathrm{~T}_{3}$ & & & \\
\hline \multirow{3}{*}{$\begin{array}{l}\text { Young's modulus } \\
\text { in flexion (GPa) }\end{array}$} & 3.56 & 12.54 & 9.12 & 6.39 & $\mathrm{~T}_{1}$ & \multirow{3}{*}{$\begin{array}{l}\mathbf{8 . 2 8} \\
{[14]}\end{array}$} & \multirow{3}{*}{$\begin{array}{l}2.49 \\
{[15]}\end{array}$} & \multirow{3}{*}{$\begin{array}{c}3.7 \\
{[15]}\end{array}$} \\
\hline & 3.56 & 10.93 & 13.11 & 8.99 & $\mathrm{~T}_{2}$ & & & \\
\hline & 3.56 & 7.35 & 9.31 & 5.78 & $\mathrm{~T}_{3}$ & & & \\
\hline
\end{tabular}

literature, for unsaturated polyester matrix composites produced by hand lay-up method.

\section{Conclusion}

The present study centered on the production and the characterization of polyester/Canarium schweinfurthii Engl cores particulates. In order to achieve this objective, an experimental approach based on the formulation and elaboration of composite samples for which the size and filler content vary, was adopted. Polyester resin was used as a matrix. For the better achievement, this study has focused on shell conditioning and sample formulation. The composites were produced by hand lay-up method, and physical-chemical and mechanical tests were carried out on previously treated and conditioned samples at room temperature, and the physical and mechanical parameters were determined. It was observed that the density varied very little in the sample field from 1200 to $1232.10 \mathrm{~kg} \cdot \mathrm{m}^{-3}$. Depending on the fillers proportions of Canarium schweinfurthii Engl cores, the greatest compressive stress at fracture was obtained at $40 \%$ fillers. Our findings also reveal that, the compressive stress at break is higher for $\mathrm{T}_{3}$ particles size, which leads us to the highest value of $199.14 \mathrm{MPa}$. Up to $45 \%$ filler content, the Young's modulus increases and reaches its maximum of 13.11 $\mathrm{GPa}$ at $45 \%$ filler content for a size $\mathrm{T}_{2}$. Basically, the static friction coefficient of the composite on wood increases with the filler content and varies from 0.30 to 0.42 . Thus, in view of the properties obtained, this composite can be used as an alternative solution for structural materials in industrial applications, such as shoe heel, house ceiling, floors for housing and table support. 


\section{Conflicts of Interest}

The authors declare no conflicts of interest regarding the publication of this paper.

\section{References}

[1] Nkouam, G.B. (2007) Conservation des fruits du karité (Vitellaria paradoxa Gaertn.) et de l'aiéle (Canarium Schweinfurthii Engl.): Isothermes de sorption d'eau et extraction des matières grasses des fruits stockés. Thèse soutenue à l'Université de Ngaoundéré.

[2] Nono, Y.J. and Kapseu, C. (1999) Problématiques du traitement et de la distribution des fruits de l'Aiélé (Canarium schweinfurthii Engl.) au Cameroun.

[3] Ehiem, J.C., Ndirika, V.I., Onwuka, U.N. and Raghavan, V. (2019) The Moisture-Dependent Flow Characteristics of Canarium schweinfurthii Engler Nuts.

[4] Yilleng, M.T., et al. (2013) Adsorption of Hexavalent Chromium from Aqueous Solution by Granulated Activated Carbon from Canarium schweinfurthii Seed Shell. Advances in Applied Science Research, 4, 89-94.

[5] Ehiem, J.C., Ndirika, V.I.O. and Raghavan, G.S.V. (2015) Frictional Properties of Canarium schweifurthii Engl. Fruits and Their Interaction with Moisture Content and Shape.

[6] Obi, O.F., Ijere, N.C. and Okechukwu, M.E. (2018) Determination of Physical and Aerodynamic Characteristics of African Olive (Canarium schweinfurthii) Nut. Agricultural Engineering International: CIGR Journal, 20, 172-179.

[7] Ehiem, J.C., Ndirika, V.I., Onwuka, U.N., Gariepy, Y. and Raghavan, V. (2019) Water Absorption Characteristics of Canarium schweinfurthii Fruits. Information Processing in Agriculture, 6, 386-395.

https://doi.org/10.1016/j.inpa.2018.12.002

[8] Ehiem, J.C., Ndirika, V.I. and Onwuka, U.N. (2016) Effect of Moisture Content on Some Physical Properties of Canarium schweinfurthii Engl. Fruits. Research in Agricultural Engineering, 62, 162-169. https://doi.org/10.17221/11/2015-RAE

[9] Shehu, U., Aponbiede, O., Ause, T. and Obiodunukwe, E.EF. (2014) Effect of Particle Size on the Properties of Polyester/Pal Kernel Shell (PKS) Particulate Composites. Journal of Materials and Environmental Science, 5, 366-373.

[10] Nwachukwu, J.C. and Osarenmwinda, J.O. (2010) Development of Composite Material from Agricultural Wastes. International Journal of Research in Africa, 3, 42-48. https://doi.org/10.4028/www.scientific.net/JERA.3.42

[11] Horrocks, R. (2001) Composites. In: Price, A.R., Ed., Fire Retardant Material, Woodhead Publishing Ltd., Cambridge, 182-201. https://doi.org/10.1533/9781855737464.182

[12] Bismarck, S., Mishra, M. and Lampke, T. (2005) Plant Fibers as Reinforcement for Green Composites. In: Mohanty, A.M., Ed., Natural Fibres, Biopolymers and Biocomposites, CRC Press, Boca Raton, 37-108. https://doi.org/10.1201/9780203508206.ch2

[13] Dieunedort, N. (2014).Caractérisation physico chimique et mécanique des coques de noix de coco nucifera du Cameroun en vue de leur utilisation dans l'élaboration des matériaux abrasifs. Thèse de Doctorat/PhD université de Dschang.

[14] Dubey, N. and Agnihotri, G. (2015) Development and Characterization of the Mi- 
drib of Coconut Palm Leaf Reinforced Polyester Composite. Computers Materials \& Continua, 45, 39-55.

[15] Prasad, A.R. and Rao, K.M. (2011) Mechanical Properties of Natural Fiber Reinforced Polyester Composites: Jowar, Sisal and Bamboo. Materials \& Design, 32, 4658-4663. https://doi.org/10.1016/j.matdes.2011.03.015 